\title{
An Ultrastructural Investigation into the Role of Calcium in Oosphere-initial Development in Saprolegnia diclina
}

\author{
BY JOHN FLETCHER* \\ Botany Department, University College, Dublin, Ireland
}

(Received 31 October 1978; revised 3 January 1979)

\begin{abstract}
Prior to formation of oosphere initials in septum-delimited oogonia of Saprolegnia diclina, the volume density (volume fraction) of central vacuoles containing characteristic clusters of electron-opaque, granular material increased from 6.0 to $54.2 \%$ whereas dense-body vesicles decreased in volume density from 30.2 to $9.0 \%$. During this time, dense-body vesicles were reduced in number by $50 \%$, their mean diameter decreased from 0.861 to $0.697 \mu \mathrm{m}$ and the percentage of vesicles with more than one dense-body granule increased from $5 \cdot 4$ to $20 \cdot 2$. The volume density of lipid bodies did not change, whilst that of the cytoplasmic matrix decreased from 40.0 to $18.2 \%$. Volume densities of mitochondria and nuclei remained constant relative to the peripheral oogonial protoplasm until central vacuoles had enlarged, but then decreased as oosphere initials formed. Small cytoplasmic vesicles were associated both with Golgi dictyosomes and with dense-body vesicles having blebbed membranes. Similar small vesicles were present close to both central vacuole membranes and oogonial walls.

Oogonia grown in calcium-deficient medium showed a high level of oogonium and oosphere abortion. Aborted oogonia showed extreme protoplast disorganization. In unaborted oogonia grown under calcium-deficient conditions, central vacuoles contained crystalline inclusions, and some oogonia did not form secondary wall layers. Organelles were of normal appearance but calcium deficiency increased the volume densities of mitochondria and nuclei at early stages of oogonial development and of dense-body vesicles and peripheral vacuoles at later stages; the volume density of lipid bodies was reduced at all stages. The numerical density of dense-body vesicles progressively increased during oogonial development and was greater at all developmental stages than in oogonia grown under conditions of calcium sufficiency. At late stages of oogonial development, calcium deficiency reduced both the mean diameter of dense-body vesicles and the fraction of them having two or more dense-body granules.
\end{abstract}

\section{INTRODUCTION}

Calcium ions may be intimately involved in control at the cellular level (Bygrave, 1978) and can influence reproduction in Oomycetes and other fungi (Bollard \& Butler, 1966; Lenny \& Klemmer, 1966; Elliott, 1972). McCann \& Stuart (1973) found $\mathrm{Ca}^{2+}$ to be essential for growth of Saprolegnia diclina. They also showed that deficiency of $\mathrm{Ca}^{2+}$ in the culture medium specifically affected the normal cleavage into oospheres of the protoplasm of developing oogonia, resulting in oogonial abortion. In the related genus Achlya, $\mathrm{Ca}^{2+}$ deficiency prevents zoospore formation (Griffin, 1966) and inhibits amino acid uptake and protein synthesis (Cameron \& LeJohn, 1972).

Formation of oosphere initials in oogonia of members of the Saprolegniaceae, including $S$. diclina, is preceded by formation of a large central vacuole or vacuole system without

* Present address: Department of Botany and Microbiology, University of the Witwatersrand, Johannesburg, Republic of South Africa.

$0022-1287 / 79 / 0000-8433 \$ 02.00$ (C) 1979 SGM 
change in oogonial size (DeBary, 1881; Humphrey, 1893; Hartog, 1895; Trow, 1899; Fletcher, 1978). Gay et al. (1971) suggested that the central vacuole system in oogonia of Saprolegnia ferax was formed by enlargement and coalescence of specialized vesicles (densebody vesicles) and showed an overall increase in vesiculation during oogonial development, but they did not distinguish in their quantitative study between dense-body vesicles and central vacuoles or investigate quantitative changes in other organelles. DeBary (1881), Hartog (1895) and Trow (1899) described formation of oosphere initials in several members of the Saprolegniaceae as involving the progressive drawing into heaps of a thin, peripheral layer of protoplasm surrounding an already fully-enlarged central vacuole. In contrast, Howard \& Moore (1970) and Gay et al. (1971) suggested, after ultrastructural studies, that oosphere initials are cut out by cleavage vacuoles that develop centrifugally while central vacuoles are still enlarging.

This paper presents qualitative and quantitative observations on the ultrastructure of developing oogonia of $S$. diclina that help to elucidate further the changes within oogonia that lead to the formation of oosphere initials. Observations on changes in oogonial ultrastructure induced by growth under conditions of $\mathrm{Ca}^{2+}$ deficiency are also included.

\section{METHODS}

Organism and culture. Stock cultures of Saprolegnia diclina Humphrey were maintained on a medium containing ( $\mathrm{g} \mathrm{l}^{-1}$ in deionized water): glucose 1.66 ; sodium glutamate 0.666 ; DL-methionine $0.016 ; \mathrm{KH}_{2} \mathrm{PO}_{4}$, $0 \cdot 046 ; \mathrm{K}_{2} \mathrm{HPO}_{4}, 0.056 ; \mathrm{MgCl}_{2} .6 \mathrm{H}_{2} \mathrm{O}, 0.33 ; \mathrm{MnCl}_{2} .4 \mathrm{H}_{2} \mathrm{O}, 0.02 ; \mathrm{CaCl}_{2} .6 \mathrm{H}_{2} \mathrm{O}, 0.006 ; \mathrm{FeCl}_{3} .6 \mathrm{H}_{2} \mathrm{O}, 0.0004$; $\mathrm{ZnSO}_{4} .7 \mathrm{H}_{2} \mathrm{O}, 0.01$; and solidified with $2 \%(\mathrm{w} / \mathrm{v})$ agar (Oxoid no. 1). Cultures for electron microscopy were grown for 5 to $10 \mathrm{~d}$ at $20^{\circ} \mathrm{C}$ in unsolidified, quarter-strength medium containing $6.85 \mu \mathrm{M}-\mathrm{CaCl}_{2}$ (medium used by McCann \& Stuart, 1973; M. McCann, personal communication) in glass Petri dishes inoculated with plugs from stock cultures (high $\mathrm{Ca}^{2+}$ regime), or in medium containing $1 \cdot 71 \mu \mathrm{M}^{-} \mathrm{CaCl}_{2}$ for $5 \mathrm{~d}$ then transferred to $\mathrm{CaCl}_{2}$-free medium for 5 to $10 \mathrm{~d}\left(\mathrm{Ca}^{2+}\right.$-free regime).

Electron microscopy. Portions of oogonia-bearing mycelium were fixed for $20 \mathrm{~min}$ in a $2 \%(\mathrm{w} / \mathrm{v})$ formaldehyde $/ 2 \%(\mathrm{v} / \mathrm{v})$ glutaraldehyde mixture, rinsed three times with water, transferred to $1 \%(\mathrm{w} / \mathrm{v})$ osmium tetroxide for $1 \mathrm{~h}$ then rinsed three times with water, all at room temperature and buffered at $\mathrm{pH} 7.2$ with $0.05 \mathrm{M}$-sodium cacodylate. Fixed material was dehydrated in an acetone/water series with retention for 2 to $4 \mathrm{~h}$ in $50 \%(\mathrm{v} / \mathrm{v})$ acetone saturated with uranyl acetate, and embedded in Araldite or Epon. Sections were stained at room temperature with $5 \%(\mathrm{w} / \mathrm{v})$ aqueous uranyl acetate for $30 \mathrm{~min}$ followed by lead citrate for $15 \mathrm{~min}$.

Stereology. Oogonia for stereological sampling were selected by light microscopy after fixation and embedding. Sampling was carried out on (i) oogonia which were already septum-delimited but in which the central vacuole was still small (vacuole diameter about $25 \%$ of the total oogonium diameter; young oogonia), (ii) septum-delimited oogonia in which the central vacuole was large (vacuole diameter about $80 \%$ of the total oogonium diameter; late pre-oosphere initial stage oogonia) and (iii) oogonia in which oosphere initials had already formed (oosphere initial stage oogonia). Exact measurements of total oogonium and central vacuole diameters of young and of late pre-oosphere initial stage oogonia were made using a light microscope with a $\times 40$ objective after trimming of blocks but before sectioning, and the fractions of the total oogonium volume occupied by central vacuoles and peripheral protoplasm, respectively, were calculated for each oogonium used. Percentage volume densities of selected organelles (volume fraction of organelle in containing protoplasm $\times 100$ ) were determined on electron micrograph prints at $\times 10000$ magnification from at least five oogonia from each $\mathrm{Ca}^{2+}$ regime at each developmental stage by point sampling methods (Weibel, 1973) using a $1 \mathrm{~cm}$ square sampling lattice, with sampling restricted to the peripheral protoplasm only. Sufficient micrographs were sampled to provide a total test point number of at least 6000 for each $\mathrm{Ca}^{2+}$ regime at each developmental stage. Mean diameters and numerical densities (number per unit volume of containing protoplasm) of the dense-body vesicle component were determined using the method described by Weibel (1973) with any non-circular profiles treated as circles of equal area. Volume density and numerical density values relative to the peripheral protoplasm in high $\mathrm{Ca}^{2+}$ regime young and late pre-oosphere initial stage oogonia were converted to values relative to the total oogonium volume (peripheral protoplasm plus central vacuoles) by multiplication by the fraction of the oogonium volume occupied by peripheral protoplasm. This conversion was made individually for each oogonium sampled. The significance of results was assessed using standard two-sample significance tests as described by Cooper (1969). Pairs of numerical density values for the same organelle at consecutive stages of development having a difference of low statistical significance $(P>0 \cdot 4)$ were combined to provide a common estimate. 
RESULTS

High $\mathrm{Ca}^{2+}$ regime

In young, septum-delimited oogonia (Fig. 1), central vacuoles contained characteristic clusters of granular material (Fig. 2). Electron-opaque granules, similar in distribution to the mottled granules described by Gay et al. (1971), were present in vacuoles of some oogonia (Fig. 10) but were not found consistently. In addition to nuclei, mitochondria, lipid bodies, dense-body vesicles, and Golgi dictyosomes with associated small vesicles (Figs 2, 4 ), the peripheral protoplasm of young oogonia contained small vacuoles (peripheral vacuoles) with clusters of granular material similar to those in central vacuoles (Fig. 3). Serial sections showed that most of the vacuole or vesicle-like profiles within the peripheral protoplasm, except for peripheral vacuoles and small vesicles similar to those associated with Golgi dictyosomes, contained dense-body granules (Figs 5,6,7). These granules were surrounded by an often irregular layer of material of greater electron opacity (Figs 3, 8, 9, 11). Some profiles of dense-body vesicles contained two dense-body granules either free (Fig. 8) or joined by electron-dense material (Fig. 9). Some dense-body vesicles showed blebbing and were associated with clusters of small vesicles (Fig. 11). In late pre-oosphere initial stage oogonia (Fig. 12) the large central vacuoles contained scattered membrane profiles and clusters of electron-opaque granular material (Fig. 15) similar to the clusters in central and peripheral vacuoles of young oogonia. Small vesicles were present closely adjacent to both the central vacuole membrane (Fig. 13) and the oogonial wall (Fig. 14). After oosphere-initial development (Fig. 16) the space between the central granule and the limiting membrane of dense-body vesicles was completely filled by electron-dense material which often showed myelin-like banding (Fig. 17) similar to that in dense-body vesicles of Saprolegnia furcata (Gay et al., 1971). The central vacuoles of oogonia appeared to be fully enlarged (Fig. 12) before the appearance of oosphere initials (Fig. 16).

The volume density of dense-body vesicles relative to the peripheral protoplasm progressively decreased from young through to oosphere initial stages, while that of lipid progressively increased (Table 1). The volume densities of mitochondria and nuclei relative to the peripheral protoplasm did not change significantly between young and late pre-oosphere initial stages despite the reduction in protoplasmic volume, but decreased between late preoosphere initial and oosphere initial stages (Table 1). The volume density of the matrix relative to the peripheral protoplasm showed a slight decrease between young and late preoosphere initial stages but this was of low statistical significance (Table 1). No significant change in matrix volume density occurred between late pre-oosphere initial and oosphere initial stages (Table 1). The volume density of central vacuoles relative to the total oogonium volume increased by $48.2 \%$ of the oogonium volume between young and late pre-oosphere initial stages (Table 1). The volume density of lipid relative to the total volume did not differ significantly between young and late pre-oosphere initial stage oogonia (Table 1). Volume densities of other organelles, and of the matrix, relative to the total oogonium volume were lower in late pre-oosphere initial stage oogonia than in young oogonia(Table 1).

The mean diameter of dense-body vesicles progressively decreased during oogonium maturation but the differences between stages were of relatively low significance (Table 2). The numerical density of dense-body vesicles relative to the peripheral protoplasm did not change significantly from young through to oosphere initial stages but decreased between young and late pre-oosphere initial stages relative to the total oogonium volume (Table 2). Of vesicle profiles that contained dense-body granule profiles, $5 \cdot 4 \pm 1 \cdot 8 \%$ (1) contained two or more granules in young oogonia, $20 \cdot 2 \pm 5 \cdot 3 \%$ (2) in late pre-oosphere initial stage oogonia and $16.5 \pm 8.5 \%$ (3) in oosphere initial stage oogonia. Values 1 and 2 differ significantly at $P<0.001$; values 2 and 3 do not differ significantly at $P=0.05$.

Precise calculation of organelle volume densities relative to the total oogonium volume for oosphere initial stage oogonia was not possible since the oogonium volume fraction 

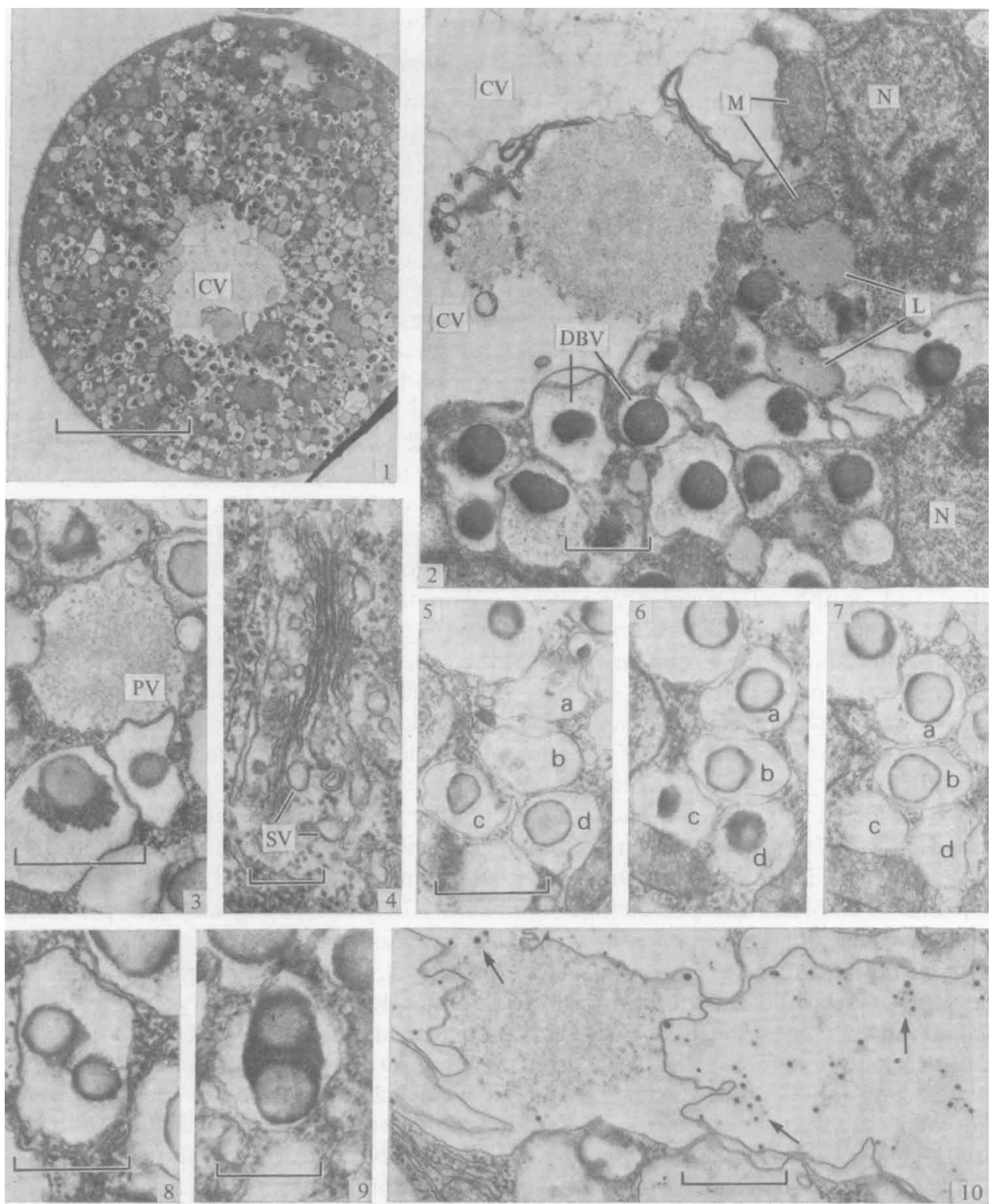

Oogonia from cultures of Saprolegnia diclina grown continuously with $6.85 \mu \mathrm{M}-\mathrm{CaCl}_{2}$. Bar markers represent $10 \mu \mathrm{m}$ in Fig. $1,1 \mu \mathrm{m}$ in Figs 2, 3 and 5, 0.5 $\mu \mathrm{m}$ in Figs 8, 9 and 10 and $0.25 \mu \mathrm{m}$ in Fig. 4.

Fig. 1. A median section of a young oogonium with a small central vacuole system (CV) and thick peripheral protoplasmic layer.

Fig. 2. Part of the central vacuole system (CV) and adjacent peripheral protoplasm of a young oogonium with nuclei $(\mathrm{N})$, mitochondria (M), lipid bodies (L) and dense-body vesicles (DBV).

Fig. 3. A small peripheral vacuole (PV) from the peripheral protoplasm of a young oogonium.

Fig. 4. A Golgi dictyosome with associated small vesicles (SV) from a young oogonium.

Figs 5,6 , 7. Serial sections of four dense-body vesicles (a, b, c and d) from a young oogonium.

Figs 8, 9. Dense-body vesicles with two dense-body granules each from a young oogonium.

Fig. 10. Vacuoles with scattered electron-opaque granules (arrowed) from a young oogonium. 

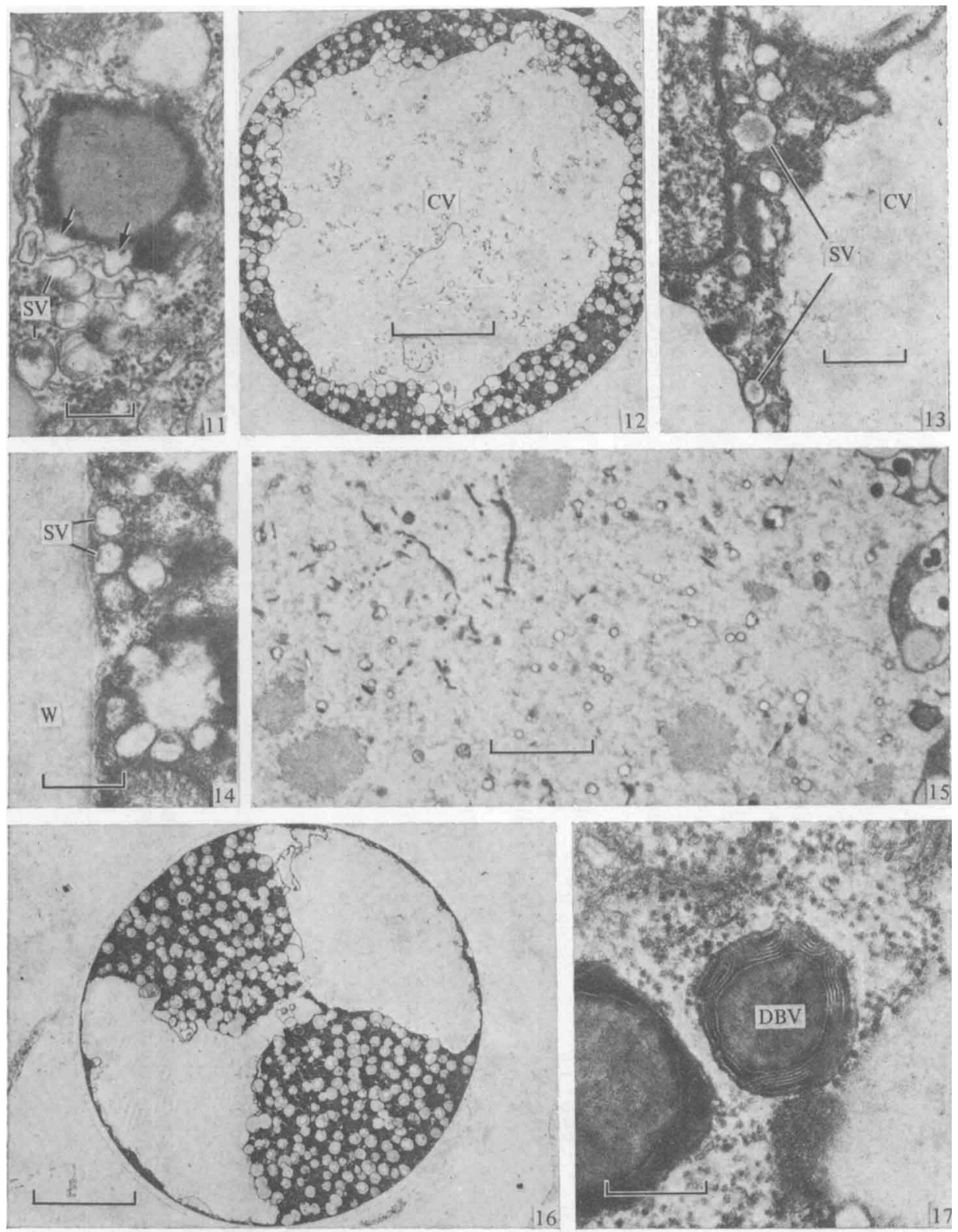

Oogonia from cultures of Saprolegnia diclina grown continuously with $6.85 \mu \mu_{\mathrm{M}-\mathrm{CaCl}_{2}}$. Bar markers represent $10 \mu \mathrm{m}$ in Figs 12 and 16, $2 \mu \mathrm{m}$ in Fig. 15, 0.5 $\mu \mathrm{m}$ in Figs 13 and 14 and 0.25 $\mu \mathrm{m}$ in Figs 11 and 17.

Fig. 11. A dense-body vesicle with blebbed membrane (arrowed) and associated small vesicles (SV).

Fig. 12. A late pre-oosphere initial stage oogonium with a large central vacuole (CV) and thin peripheral protoplasmic layer.

Fig. 13. Small vesicles (SV) close to the central vacuole (CV) of a late pre-oosphere initial stage oogonium.

Fig. 14. Small vesicles (SV) close to the wall (W) of a late pre-oosphere initial stage oogonium.

Fig. 15. Part of the central vacuole of a late pre-oosphere initial stage oogonium with both dispersed and clustered electron-opaque, granular material.

Fig. 16. An oosphere initial stage oogonium with two initials.

Fig. 17. A dense-body vesicle (DBV) from an oosphere initial stage oogonium. 


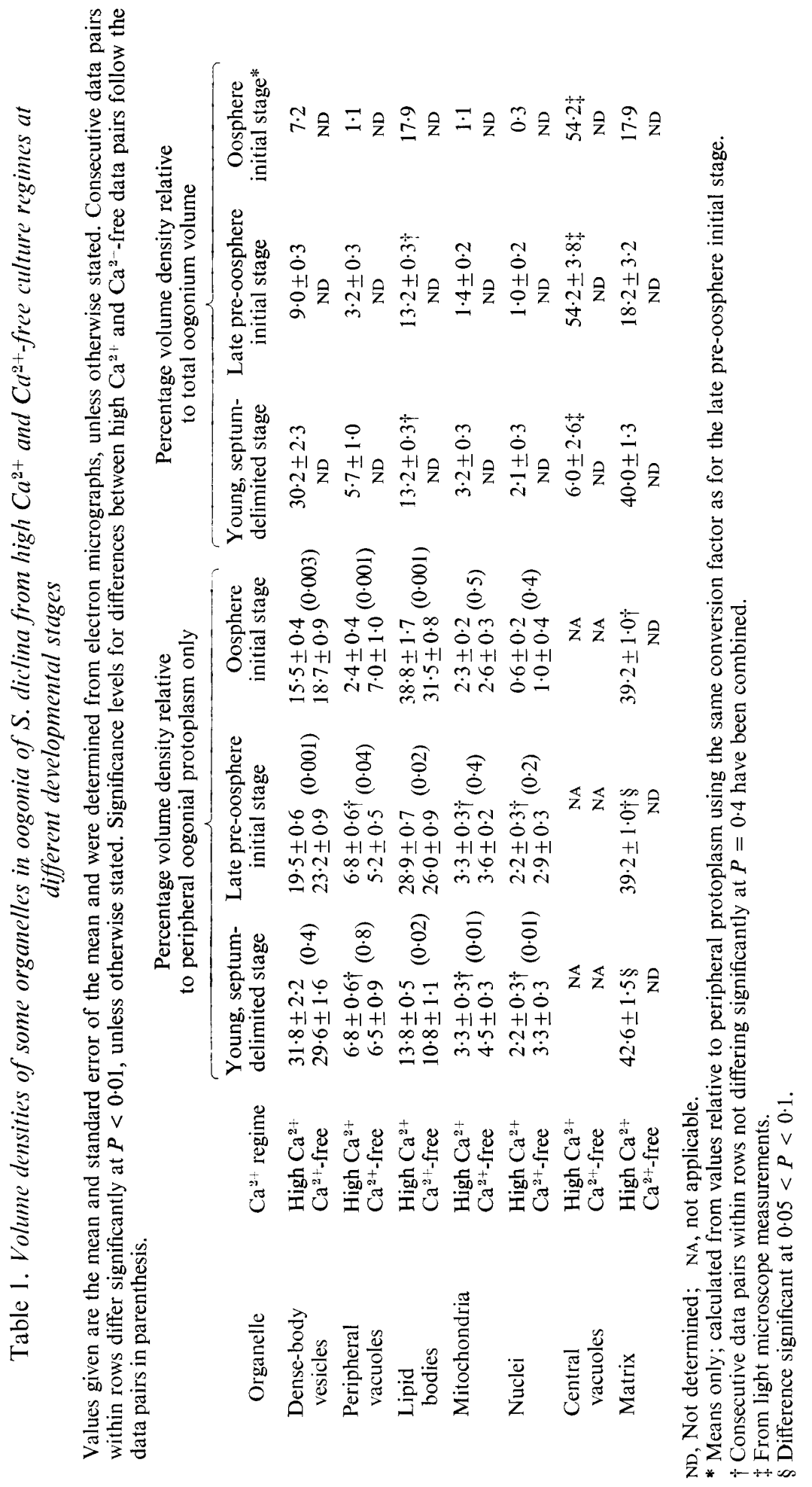




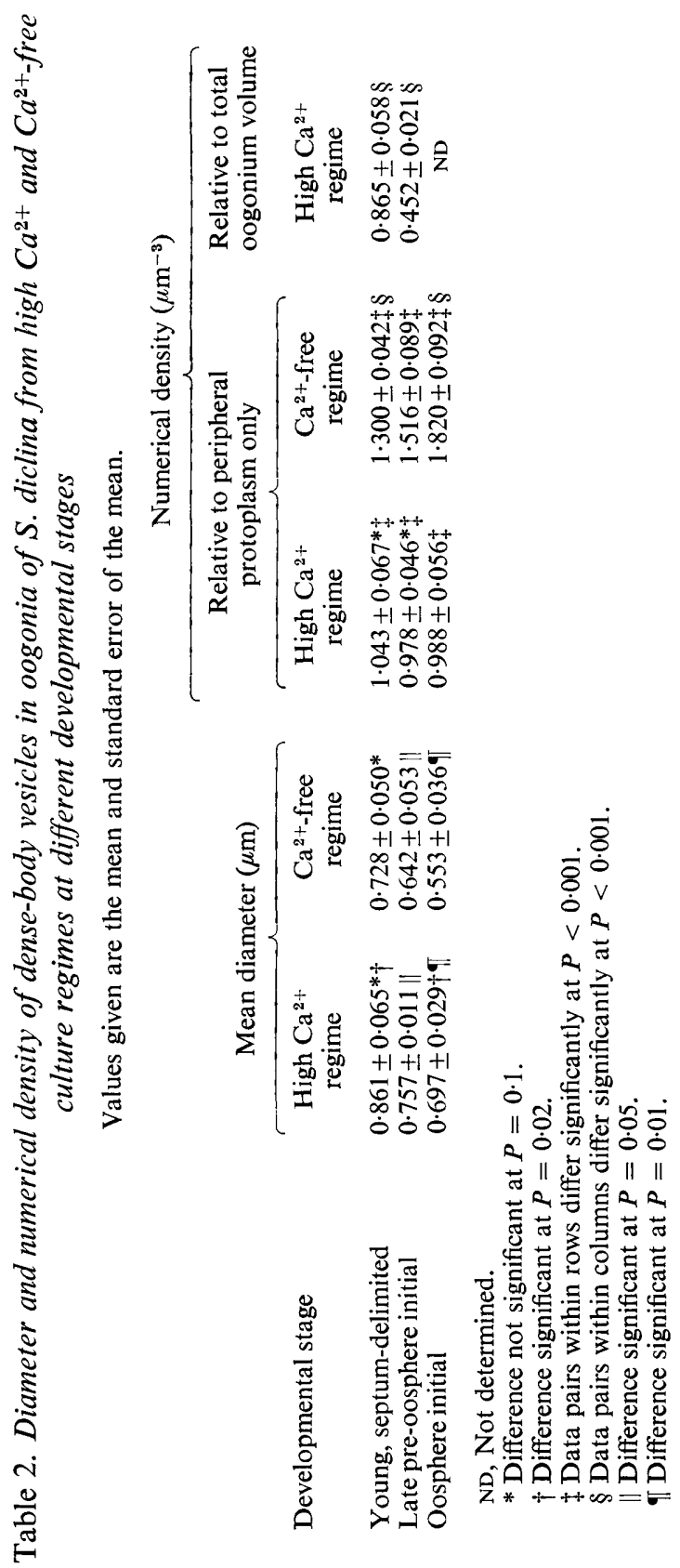


Table 3. Effect of $\mathrm{CaCl}_{2}$ concentration on oogonia and oospores of S. diclina

Cultures were grown for $5 \mathrm{~d}$ in medium 1 then for $10 \mathrm{~d}$ in medium 2 before sampling, with sampling restricted to mycelial growth made in medium 2 . Values given are the mean and standard deviation for eight replicates with 125 oogonia and 40 oospheres (oospores) examined per replicate.

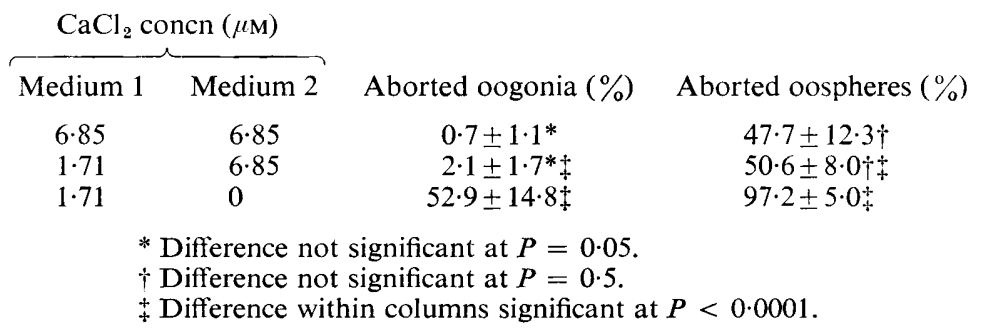

occupied by the irregularly-shaped, central vacuole could not easily be measured. Table 1 gives mean values for volume densities in oosphere initial stage oogonia relative to the total oogonium volume determined using a conversion factor derived from measurements on late pre-oosphere initial stage oogonia. If a further increase in the volume fraction occupied by the central vacuole occurs between late pre-oosphere initial and oosphere initial stages, these values will be overestimates.

\section{$\mathrm{Ca} a^{2+}$-free regime}

Almost all oogonia formed in cultures grown under the $\mathrm{Ca}^{2+}$-free regime eventually showed abnormalities detectable by light microscopy. The percentage of oogonia that aborted (oogonia forming no recognizable oospheres or oospores) was increased about 50fold relative to that in cultures grown continuoulsy with high $(6.85 \mu \mathrm{M}) \mathrm{Ca}^{2+}$ (Table 3$)$. In the remaining oogonia that did form oospheres, the percentage of oospheres that aborted (oospheres or oospores not showing normal maturation; Fletcher, 1978) reached almost $100 \%$ (Table 3). Initial growth in low $\mathrm{Ca}^{2+}$ medium did not significantly increase abortion rates when followed by transfer to high $\mathrm{Ca}^{2+}$ medium (Table 3 ).

Aborted oogonia showed extreme protoplast degeneration (Fig. 18). Crystalline inclusions were present in central vacuoles of unaborted oogonia (Fig. 20) but organelles of unaborted oogonia appeared normal (Fig. 19). About $50 \%$ of the oogonia examined at late preoosphere initial stage had failed to form secondary wall layers (Figs 21, 22) and had small, cytoplasmic vesicles close to their walls (Fig. 22).

Volume densities of dense-body vesicles and of peripheral vacuoles were unaffected by growth under the $\mathrm{Ca}^{2+}$-free regime in young oogonia but the volume density of dense-body vesicles was increased in late pre-oosphere initial stage oogonia and the volume densities of both organelles were increased in oosphere initial stage oogonia (Table 1). Volume densities of mitochondria and nuclei were increased in young oogonia but were unaffected in late pre-oosphere initial and in oosphere initial stage oogonia (Table 1). The density of lipid was reduced at all three developmental stages (Table 1). The mean diameter of dense-body vesicles was reduced in late pre-oosphere initial and in oosphere initial stage oogonia but was not significantly affected in young oogonia (Table 2). The numerical density of dense-body vesicles increased progressively during oogonial development and was greater at all stages than in oogonia from cultures grown under the high $\mathrm{Ca}^{2+}$ regime (Table 2). The percentage of vesicle profiles that contained dense-body granule profiles having two or more granule profiles each in young oogonia $(5 \cdot 1 \pm 2 \cdot 3)$ did not differ significantly $(P>0 \cdot 5)$ from that in young oogonia grown under the high $\mathrm{Ca}^{2+}$ regime. The percentage in oosphere initial stage oogonia $(8.5 \pm 3.4)$ was significantly lower $(P<0.01)$ than in high $\mathrm{Ca}^{2+}$ regime oogonia at the same developmental stage. 

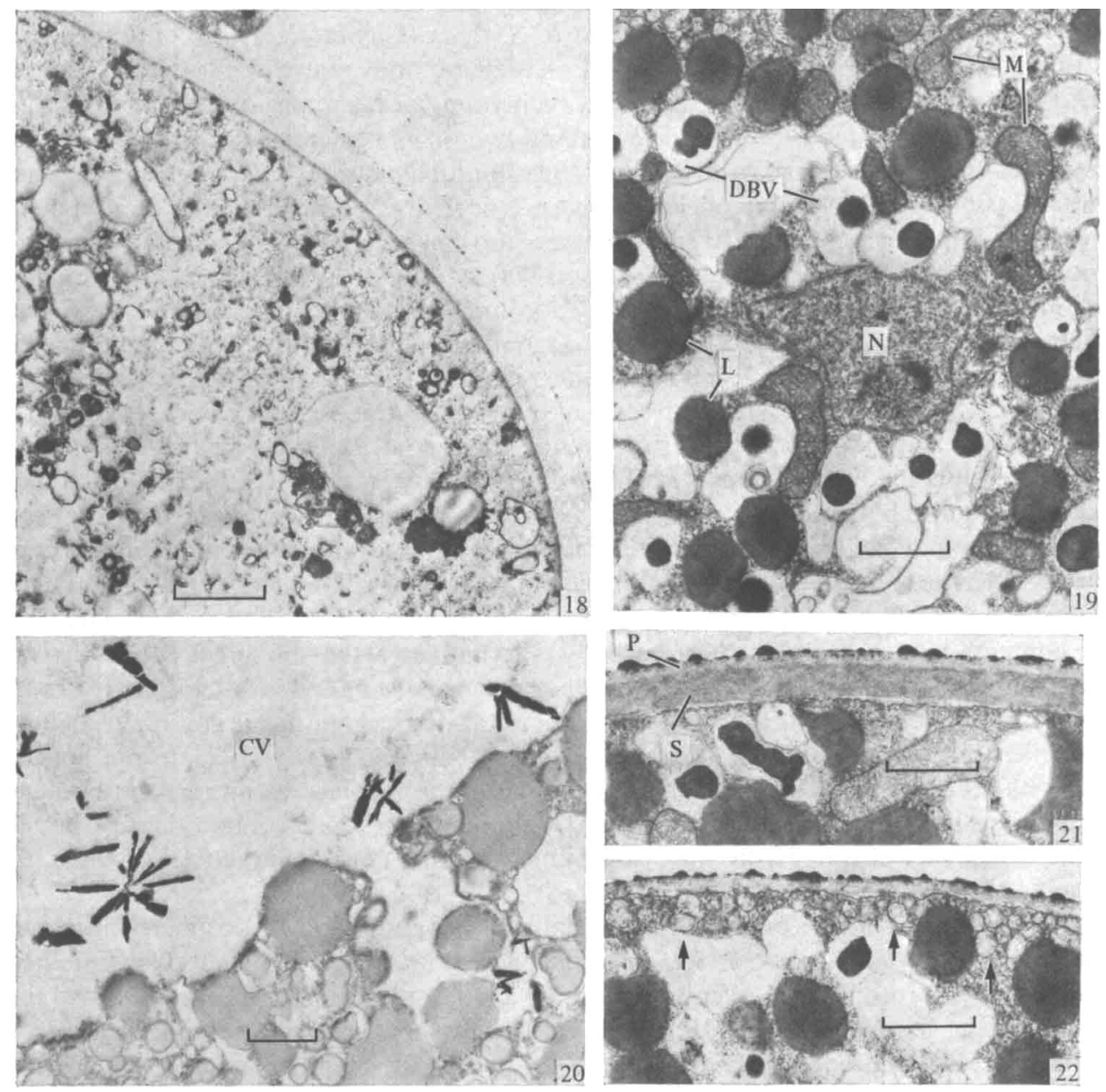

Oogonia from cultures of Saprolegnia diclina either grown for $5 \mathrm{~d}$ with $1.71 \mu \mathrm{M}-\mathrm{CaCl}_{2}$ then in $\mathrm{CaCl}_{2}$ free medium for 5 to $10 \mathrm{~d}$ (Figs 18, 19, 20, 22) or grown continuously with $6 \cdot 85 \mu \mathrm{M}-\mathrm{CaCl}_{2}$ (Fig. 21). Bar markers represent $2 \mu \mathrm{m}$ in Fig. 18 and $1 \mu \mathrm{m}$ in the remaining figures.

Fig. 18. Part of an aborted oogonium.

Fig. 19. Protoplast detail from an unaborted, late pre-oosphere initial stage oogonium with nucleus $(N)$, mitochondria (M), dense-body vesicles (DBV) and lipid bodies (L).

Fig. 20. Crystalline inclusions in the central vacuole (CV) of an oogonium (section unstained).

Fig. 21. Primary (P) and normally developed, secondary (S) wall layers of a late pre-oosphere initial stage oogonium.

Fig. 22. Peripheral zone of a late pre-oosphere initial stage oogonium with primary wall layer only and small vesicles (arrowed) close to the wall.

\section{DISCUSSION}

The presence of similar clusters of granular material in central and peripheral vacuoles of young, septum-delimited oogonia and in the central vacuoles of late pre-oosphere initial stage oogonia suggests that the large central vacuoles of late pre-oosphere initial stage oogonia form by enlargement of the small central vacuoles of young oogonia and that some peripheral vacuoles of young oogonia may become incorporated into the central vacuoles. The decrease in volume density of dense-body vesicles during oogonial development suggests transfer of dense-body vesicle contents into the developing central vacuoles. 
Direct fusion of dense-body vesicles with the enlarging central vacuoles has been suggested for central vacuole development in oogonia of $S$. ferax (Gay et al., 1971), but no evidence for this, such as fusion profiles or incorporation of dense-body granules into central vacuoles, was observed in $S$. diclina. The increase between young and late pre-oosphere initial stages in the percentage of dense-body vesicles having two or more dense-body granules suggests that dense-body vesicles in $S$. diclina may fuse mutually during oogonium development. Mutual fusion of dense-body vesicles has been reported to occur at a later developmental stage, during maturation of cleaved oospheres into oospores, in S. terrestris (Howard \& Moore, 1970) and S. furcata (Beakes \& Gay, 1978). Mutual fusion of dense-body vesicles in oogonia of $S$. diclina could at least partially account for the reduction in numerical density of dense-body vesicles relative to the total oogonium volume between young and late preoosphere initial stages. Such fusion should also increase the dense-body vesicle size, but no such increase was observed. Although some of the small, cytoplasmic vesicles seen in oogonia of $S$. diclina are probably Golgi-derived vesicles that contribute to oogonial wall development, as in oogonia of S. furcata (Heath et al., 1971; Gay et al., 1971), the blebbed appearance of the limiting membranes of some dense-body vesicles in S. diclina suggests that some small vesicles may be formed by budding from dense-body vesicles, thus reducing the densebody vesicle size. Fusion with the vacuolar membrane of small vesicles derived from densebody vesicles could provide a mechanism for transfer of the dense-body vesicle membrane and contents to developing central vacuoles alternative to that of direct fusion of entire dense-body vesicles with central vacuoles. The presence of small vesicles close to the central vacuole membrane is consistent with this. The total decrease in mean volume densities of organelles relative to the total oogonium volume between young and late pre-oosphere initial stages $(26.6 \%)$ is insufficient to account for the increase in mean central vacuole volume density $(48 \cdot 2 \%$ ). Additional reduction of protoplasmic volume density possibly occurs by transfer of water from the cytoplasmic matrix to developing central vacuoles, thus reducing the matrix volume.

The appearance of late pre-oosphere initial stage oogonia and of oosphere initial stage oogonia suggests that, at least in S. diclina, oosphere initials form by the drawing into heaps of a peripheral protoplasmic layer after central vacuole enlargement. Fletcher's (1978) timelapse study of living oogonia of $S$. diclina, although showing a diffuse appearance to the central vacuole outline shortly before the formation of oosphere initials, supports the heaping hypothesis (DeBary, 1881; Hartog, 1895; Trow, 1899) rather than the cleavage hypothesis (Howard \& Moore, 1970; Gay et al., 1971) for at least the major part of the process of oosphere initial formation.

The protoplasts of oogonia of Saprolegnia spp. are cleaved into oospheres by eventual fusion of central vacuole membranes with the oogonium plasmalemma (Howard \& Moore, 1970; Gay et al., 1971). As pointed out by Gay \& Greenwood (1966) for sporangia of $S$. ferax, where a similar cleavage process occurs during formation of zoospores, fusion of central vacuole membranes with the plasmalemma membrane, with the central vacuole membrane becoming incorporated into the plasmalemmas of the cleavage products, suggests a similarity in structure between the central vacuole and plasmalemma membranes. The plasmalemma membrane in fungal hyphae, including hyphae of Oomycetes, is probably derived from Golgi cisternae (Girbardt, 1969; Grove et al., 1970; Heath et al., 1971). Cleavage vesicle (vacuole) membranes which eventually fuse with the plasmalemma membrane may be derived from Golgi cisternae in sporangia of Phytophthora parasitica (Hohl \& Hamamoto, 1967) and Thamnidium elegans (Fletcher, 1973). The enlargement of the central vacuoles (cleavage vacuoles) in oogonia of $S$. diclina by fusion with them of small vesicles derived from dense-body vesicles suggests a radically different mode of cleavage vacuole development, unless dense-body vesicles themselves are ultimately derived from Golgi dictyosomes.

Data presented here (Table 1) show that except for central vacuoles and lipid bodies, 
organelle volume densities relative to the total oogonium volume decrease during oogonial development. The decrease in nuclear volume density is consistent with the well-documented breakdown of supernumary nuclei during oogonial development (Dick \& Win-Tin, 1973). The increase in nuclear volume that occurs in the early stages of nuclear division in oogonia of Saprolegnia spp. (Howard \& Moore, 1970; Beakes \& Gay, 1977) is possibly completed and the breakdown of supernumary nuclei already well advanced in $S$. diclina by the late pre-oosphere initial stage. A reduction in the number of mitochondria, possibly associated with the onset of dormancy, occurs during oospore maturation in S. furcata (Beakes \& Gay, 1978). The reduction in the volume density of mitochondria relative to peripheral protoplasm between the late pre-oosphere initial stage and the oosphere initial stage in oogonia of $S$. diclina is possibly a preliminary stage of a similar reduction of the number of mitochondria in this species.

Quantitative effects of $\mathrm{Ca}^{2+}$ deficiency on dense-body vesicles reported here-increased volume density at late pre-oosphere initial and at oosphere initial stages, increase in numerical density between young and late pre-oosphere initial stages and the reduced percentage of dense-body vesicles with more than one dense body granule in oosphere initial stage oogonia - suggests that transfer of dense-body contents to developing central vacuoles and mutual fusion of dense-body vesicles may be partially inhibited by growth under $\mathrm{Ca}^{2+}$ deficient conditions. It has been suggested that dense-body granules are composed of phospholipid (Gay et al., 1971; Gay, 1972) and that they may be important suppliers of endogenous energy during periods of high cellular activity such as oogonial cleavage (Beakes \& Gay, 1978). If this is so, and if dense-body vesicles are involved in development of the central vacuole in oogonia of $S$. diclina as proposed here, any disturbance of normal dense-body vesicle behaviour, such as that observed here under $\mathrm{Ca}^{2+}$-deficient conditions, might be expected to seriously affect oogonial development. Wall development in oogonia of Saprolegnia spp. is thought to involve wall vesicles (Gay et al., 1971; Heath et al., 1971), similar in appearance to the small cytoplasmic vesicles found adjacent to oogonial walls of $S$. diclina, that release their contents by fusion with the oogonial plasmalemma. $\mathrm{Ca}^{2+}$ deficiency inhibits exocytotic release of secretory vesicle contents in a range of cell types (Douglas, 1974). The release of wall-vesicle contents involved in oogonial wall synthesis might be similarly inhibited by $\mathrm{Ca}^{2+}$ deficiency in some oogonia, inhibiting normal secondary wall development. Absence of a significant effect of $\mathrm{Ca}^{2+}$ deficiency on nuclear and mitochondrial volume densities in oosphere initial stage oogonia might indicate an ability of the mechanisms that control quantitative changes occurring in normally developing oogonia grown in high $\mathrm{Ca}^{2+}$ medium to compensate for initially aberrantly high nuclear and mitochondrial numbers in oogonia from cultures grown under conditions of $\mathrm{Ca}^{2+}$ deficiency. Crystalline inclusions in central vacuoles of oogonia might be present in crystalline form in living oogonia or might represent soluble-phase vacuolar components deposited as crystals during specimen preparation.

Mitochondrion-controlled cytosol $\mathrm{Ca}^{2+}$ concentration is believed to be involved in the control of cell activity through a wide range of $\mathrm{Ca}^{2+}$-dependent functions, including activation or inhibition of enzyme systems, activation of microfilaments, functioning of cyclic nucleotides and several membrane-linked functions (Carafoli, 1974; Berridge, 1976; Bygrave, 1978). $\mathrm{Ca}^{2+}$ deficiency can inhibit pyruvate dehydrogenase-mediated formation of acetyl-CoA required for fatty acid and lipid synthesis (Randle et al., 1974). Inhibition of pyruvate dehydrogenase activity by $\mathrm{Ca}^{2+}$ deficiency in $S$. diclina could affect synthesis of dense-body granule phospholipids and might also account for the observed reduction in volume density of lipid bodies in oogonia from cultures grown under $\mathrm{Ca}^{2+}$-deficient conditions. $\mathrm{Ca}^{2+}$ deficiency might inhibit uptake of amino acid constituents of the growth medium by disturbing the normal cell membrane integrity and function in $S$. diclina, and hence inhibit protein synthesis, as suggested by Cameron \& LeJohn (1972) for Achlya. Probably, the overall effect of $\mathrm{Ca}^{2+}$ deficiency on oogonia of $S$. diclina is the cumulative 
result of the disturbance by $\mathrm{Ca}^{2+}$ deficiency of a wide range of $\mathrm{Ca}^{2+}$-dependent functions, many not yet investigated in Saprolegnia or related genera.

This work was supported by a Post Doctoral Research Fellowship from the National Science Council of Ireland.

\section{REFERENCES}

Beakes, G. W. \& Gay, J. L. (1977). Gametangial nuclear division and fertilization in Saprolegnia furcata as observed by light and electron microscopy. Transactions of the British Mycological Society 69, 459-471.

Beakes, G. W. \& GaY, J. L. (1978). Light and electron microscopy of oospore maturation in Saprolegnia furcata. I. Cytoplasmic changes. Transactions of the British Mycological Society 71, $11-24$.

Berridge, M. J. (1976). Calcium, cyclic nucleotides and cell division. Symposia of the Society for Experimental Biology 30, 219-232.

Bollard, E. G. \& Butler, G. W. (1966). Mineral nutrition of plants. Annual Review of Plant Physiology 17, 77-112.

Bygrave, F. L. (1978). Mitochondria and the control of intracellular calcium. Biological Reviews 53, 43-79.

Cameron, L. E. \& LeJohn, H. B. (1972). On the involvement of calcium in amino acid transport and growth of the fungus Achlya. Journal of Biological Chemistry 247, 4729-4739.

Carafoli, E. (1974). Mitochondrial uptake of calcium ions and the regulation of cell function. Biochemical Society Symposia 39, 89-109.

COOPER, B. E. (1969). Statistics for Experimentalists. Oxford: Pergamon Press.

DeBary, A. (1881). Untersuchungen über die Peronosporeen und Saprolegnieen und die Grundlagen eines natürlichen Systems der Pilze. Abhandlungen herausgegeben von der Senckenbergischen naturforschenden Gesellschaft 12, 225 370.

Dick, M. W. \& WiN-Tin (1973). The development of cytological theory in the Oomycetes. Biological Reviews 48, 133-158.

Douglas, W. W. (1974). Involvement of calcium in exocytosis and the exocytosis-vesiculation sequence. Biochemical Society Symposia 39, 1-28.

Elliott, C. G. (1972). Calcium chloride and growth and reproduction of Phytophthora cactorum. Transactions of the British Mycological Society 58, 169-172.

FletCHER, J. (1973). Ultrastructural changes associated with spore formation in sporangia and sporangiola of Thamnidium elegans Link. Annals of Botany 37, 963-971.

Fletcher, J. (1978). Timing of events during oospore genesis in Saprolegnia diclina. Transactions of the British Mycological Society 70, $417-422$.

GAY, J. L. (1972). X-ray microanalysis in the development of oospores of the fungus Saprolegnia. Micron 3, 139-143.

Gay, J. L. \& Greenwood, A. D. (1966). Structural aspects of zoospore production in Saprolegnia ferax with particular reference to the cell and vacuolar membranes. Colston Papers 18, 95-110.

Gay, J. L., Greenwood, A. D. \& Heath, I. B. (1971). The formation and behaviour of vacuoles (vesicles) during oosphere development and zoospore germination in Saprolegnia. Journal of General Microbiology 65, 233-241.

GirbardT, M. (1969). Die Ultrastructur der Apikalregion von Pilzhyphen. Protoplasma 67, 413-447.

Griffin, D. H. (1966). Effect of electrolytes on differentiation in Achlya sp. Plant Physiology 41, 1254-1256.

Grove, S. N., Bracker, C. E. \& Morre, D. J. (1970). An ultrastructural basis for hyphal tip growth in Pythium ultimum. American Journal of Botany 57, 245-266.

Hartog, M. (1895). On the cytology of the vegetative and reproductive organs of the Saprolegniaceae. Transactions of the Royal Irish Academy 30, 649-708.

Heath, I. B., Gay, J. L. \& Greenwood, A. D. (1971). Cell wall formation in the Saprolegniales: cytoplasmic vesicles underlying developing walls. Journal of General Microbiology 65, 225-232.

Нонl, H. R. \& Намамото, S. T. (1967). Ultrastructural changes during zoospore formation in Phytophthora parasitica. American Journal of Botany 54, 1131-1139.

Howard, K. L. \& Moore, R. T. (1970). Ultrastructure of oogonia in Saprolegnia terrestris. Botanical Gazette 131, 311-336.

Humphrey, J. E. (1893). The Saprolegniaceae of the United States, with notes on other species. Transactions of the American Philosophical Society 17, 63-148.

Lenny, J. F. \& Klemmer, H. W. (1966). Factors controlling sexual reproduction and growth in Pythium graminicola. Nature, London 209, 1365 1366.

McCann, M. \& Stuart, M. (1973). The effect of calcium on sexual reproduction in Saprolegnia diclina. Proceedings of the Society for General Microbiology 1, 33 .

Randle, P. J., Denton, R. M., Pask, H. T. \& Severson, D. L. (1974). Calcium ions and the regulation of pyruvate dehydrogenase. Biochemical Society Symposia 39, 75-88.

Trow, A. H. (1899). Observations on the biology and cytology of a new variety of Achlya americana. Annals of Botany 13, 131-179.

WeIBEL, E. R. (1973). Stereological techniques for electron microscopic morphometry. In Principles and Techniques of Electron Microscopy. Biological Applications, vol. 3, pp. 237-96. Edited by M. A. Hyatt. New York: Reinhold. 